San Jose State University

SJSU ScholarWorks

Master's Theses

Master's Theses and Graduate Research

1989

\title{
Perceptions of school principal communication effectiveness and teacher satisfaction on the job
}

Kanda W. Whaley

San Jose State University

Follow this and additional works at: https://scholarworks.sjsu.edu/etd_theses

\section{Recommended Citation}

Whaley, Kanda W., "Perceptions of school principal communication effectiveness and teacher satisfaction on the job" (1989). Master's Theses. 3120.

DOI: https://doi.org/10.31979/etd.swbv-2h88

https://scholarworks.sjsu.edu/etd_theses/3120

This Thesis is brought to you for free and open access by the Master's Theses and Graduate Research at SJSU ScholarWorks. It has been accepted for inclusion in Master's Theses by an authorized administrator of SJSU ScholarWorks. For more information, please contact scholarworks@sjsu.edu. 


\section{INFORMATION TO USERS}

The most advanced technology has been used to photograph and reproduce this manuscript from the microfilm master. UMI films the text directly from the original or copy submitted. Thus, some thesis and dissertation copies are in typewriter face, while others may be from any type of computer printer.

The quality of this reproduction is dependent upon the quality of the copy submitted. Broken or indistinct print, colored or poor quality illustrations and photographs, print bleedthrough, substandard margins, and improper alignment can adversely affect reproduction.

In the unlikely event that the author did not send UMI a complete manuscript and there are missing pages, these will be noted. Also, if unauthorized copyright material had to be removed, a note will indicate the deletion.

Oversize materials (e.g., maps, drawings, charts) are reproduced by sectioning the original, beginning at the upper left-hand corner and continuing from left to right in equal sections with small overlaps. Each original is also photographed in one exposure and is included in reduced form at the back of the book. These are also available as one exposure on a standard $35 \mathrm{~mm}$ slide or as a $17^{\prime \prime} \times 23^{\prime \prime}$ black and white photographic print for an additional charge.

Photographs included in the original manuscript have been reproduced xerographically in this copy. Higher quality 6 " $\times 9$ " black and white photographic prints are available for any photographs or illustrations appearing in this copy for an additional charge. Contact UMI directly to order.

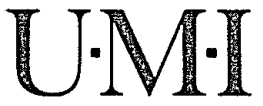


Order Number 1997854

Perceptions of school principal communication effectiveness and teacher satisfaction on the job

Whaley, Kanda Winette, M.A.

San Jose State University, 1989

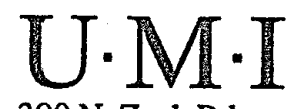

300 N. Zeeb Rd.

Ann Arbor, MI 48106 
. 


\title{
PERCEPTIONS OF SCHOOL PRINCIPAI \\ COMMUNICATION EFFECTIVENESS \\ AND TEACHER SATISFACTION ON THE JOB
}

\author{
A Thesis \\ Presented to \\ The Faculty of the Communication Studies Department \\ San Jose State University
}

In Partial Fulfillment

of the Requirements for the Degree

Master of Arts

B y

Kanda W. Whaley

May, 1989 
APPROVED FOR THE COMMUNICATION STUDIES DEPARTMENT

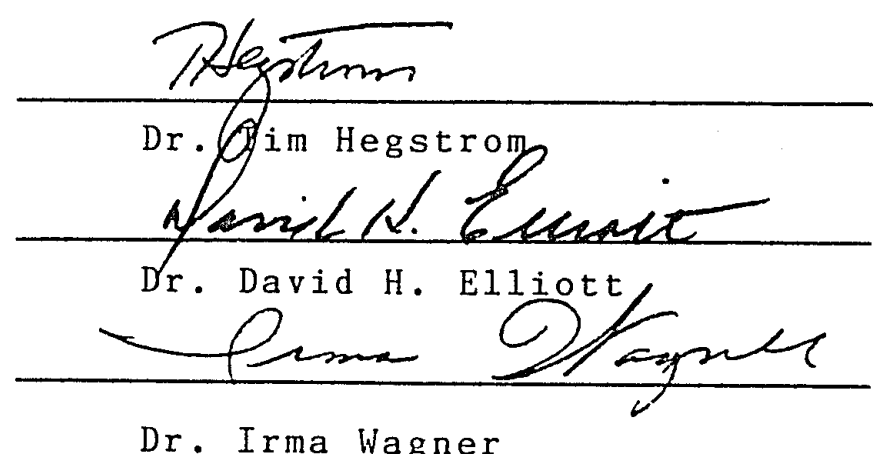

Dr. Irma Wagner

APPROVED FOR THE UNIVERSITY

Shame It Etagere 


\section{ABSTRACT}

PERCEPTIONS OF SCHOOL PRINCIPAL COMMUNICATION EFFECTIVENESS AND TEACHER SATISFACTION ON THE JOB

by Kanda W. Whaley

The purpose of this thesis was to determine whether or not a relationship exists between perceptions of school principals' communication effectiveness and teacher satisfaction on the job. Predictor variables in a canonical correlation analysis included mission, goals, feedback, rewards, and support. Criterion variables were identified as group satisfaction and personal satisfaction.

The sample for this study included 133 elementary school teachers from Santa Cruz and Santa Clara Counties in California. Each teacher responded to his/her principal's communication effectiveness through the use of the Leadership Survey (Wilson Learning Corporation, 1981). Results indicate that, for the respondents, there is a significant correlation between how teachers perceive their principals' communication and how satisfied they are on the job. In addition, results suggest that communication of feedback and rewards are the best predictors of satisfaction, and mission and goals are the least signifi-. cant predictors. 


\section{ACKNOWLEDGMENTS}

I would like to express my sincere appreciation to the wonderful people who helped with this research. As committee members, Tim Hegstrom, Dave Elliott, and Irma Wagner provided invaluable guidance and support. No one is more approachable than Tim Hegstrom. He spent an incredible amount of time helping me with this research, often making me feel as though $I$ was his only student. His high expectations, coupled with words of encouragement, allowed me to reach my full potential.

Dave Elliott is another example of one who always managed to fit me into his busy schedule. His attitudes about research and teaching have had a positive influence on me and stimulated my thinking throughout graduate school.

It was a great pleasure to have Irma Wagner on my committee and to receive such valuable input from an expert in the field of administration and higher education. Her knowledge of research and educational leadership helped to clarify and enrich this study.

I would also like to thank Brad Lashbrook for providing the research instrument and data, without which this research could not have been done.

Just as I was beginning to think I would never get my data analyzed, Bala Akella and his associates in 
Academic Computing Services came to my rescue. Their expertise in editing computer programs saved me hours of further frustration.

I'1l always be grateful to the following people for expressing confidence in me: Edwina Stoll, Signe Larkin, Susan Taylor, Pamela Oleson, Kris Adams, Cecilia Regan, Gary Miller, Beth Von Till, ar: Jo Sprague. Finally, I want to express my love and appreciation to my husband, Harold, and children, Derek and Jenna. Harold was a constant source of support and encouragement. He helped in any way he could, from rearranging his schedule to keeping the children entertained. Derek and Jenna are too young to fully grasp all this, but they both deserve awards for their patience and understanding. They managed to keep complaints to a minimum when Mommy had to work instead of play. You three are so special and I love you very much. 
I. INTRODUCTION . . . . . . . . . . . . . . 1

Overview . . . . . . . . . . . . . 1

Statement of the Problem . . . . . . 5

Review of Literature . . . . . . . . 5

Statement of the Research Questions. . . 28

Rationale... . . . . . . . . . 29

II. METHODS . . . . . . . . . . . . 32

The Survey Instrument . . . . . . . . 32

The Respondents . . . . . . . . . 38

The Procedure . . . . . . . . . . . 39

The Methods of Data Analysis . . . . . 40

III. RESULTS . . . . . . . . . . . . . 42

Preliminary Analysis . . . . . . . 42

Primary Analysis . . . . . . . . . 46

IV. DISCUSSION . . . . . . . . . . . 56

Conclusions. . . . . . . . . . 56

Limitations . . . . . . . . . . . 63

Recommendations for Further Research . . 65 
Page

REFERENCES • • • • • . . . . . . . . . . . . . 68

APPENDICES •. . . . . . . . . . . . . . . . . . . 76

A. The Survey Instrument . . . . . . . . . . 77

B. Leadership Survey Questions Pertaining to

Each Variable . . . . . . . . . . . . 83

vii 
TABLE

1. Leadership Survey Norms . . . . . . . . . 34

2. Leadership Survey Norms . . . . . . . . . 35

3. Reliability Estimates for the Leadership Survey Measures - June 1, 1981 . . . . . . . 36

4. Demographic Data for the Respondent Pool . . . 43

5. Leadership Survey Descriptive Data . . . . . 45

6. Correlation Coefficients . . . . . . . . 4 47

7. Canonical Correlation Analysis . . . . . . . 48

8. T-Tests for County . . . . . . . . . . 50

9. T-Tests for Sex... . . . . . . . . 51

10. Analysis of Variance for Culture by Age . . . . 52

11. T-Tests for Organizations . . . . . . . . . 54

12. Comparison of Perceptions of Communication Effectiveness and Job Satisfaction . . . . . 61

13. Comparison of Predictors of Culture . . . . . . 62 


\section{LIST OF FIGURES}

Page

Figure

1. Performance System Mode1 . . . . . . . . 


\section{CHAPTER I}

\section{Introduction}

\section{Overview}

Over the past decade, the educational community has centered attention on effective teaching. New requirements for teacher certification have been imposed, stricter guidelines for teacher evaluations have been set, and longer school days and school years have been mandated in several states. Critics claim, however, that education in the United States has failed badly. In recent years, dozens of reports from national, regional, state and local groups have reviewed the condition of education. Most draw the same conclusion: Education has been ineffective from kindergarten through the university level. Criticisms have focused on the quality of curriculum, the quality of teachers and teacher education programs, low test scores, and undereducated school graduates.

In addition to concentrating on effective teaching, experts have recently begun to examine leadership in the schools as another way of dealing with the education crisis. For many years, literature in the field of organizational communication has pointed to leadership as a major concern in organizations. Rescarch during the past few years has focused on the importance of leadership among school principals (Brandt, 1987; Donaldson, 1987; Fairman \& Clark, 1985; 
Ford, 1987; Leithwood, 1987; Peterson, 1986; Reil1y, 1986). As a result of this research, several steps have been taken to improve leadership in the schools. Principals' centers and academies have sprung up throughout the country within the last six years (Donaldson, 1987). This movement is frequently led by principals themselves. One such facility is the Maine Principals Academy which was designed to provide principals with the information and support needed to take charge of their own professional development. Another organization, the California School Leadership Academy (CSLA) helps school administrators grow to peak levels of personal and professional performance.

In addition, several measures have been designed to assess principal effectiveness. The Principal Profile (Leithwood, 1987) defines principals' growth in effectiveness along four dimensions, and helps administrators link appraisal results to school improvement efforts. The Principal Instructional Management Rating Scale (Hallinger \& Murphy, 1987) is a self-report that can be used to assess principal instructional leadership behavior. The Effective Schools Instrument (Brandt, 1987) measures nine areas, including teachers' perceptions of a positive learning environment and principals' instructional leadership. The latter questionnaire was used to gather data from one hundred schools over a three-year period. This study is particularly noteworthy because researchers concluded that 
in schools with strong instructional leadership, individual student scores go up over time.

One result of the recent interest in school leadership is a concern about administrative attrition. Estimates of administrative turnover by the end of the decade run as high as seventy percent of all administrators (Peterson, 1986). This implies that how administrators are selected and trained over the next few years could have a significant impact on the success or failure of our schools by the turn of the century.

While much attention has been given to leadership in the schools, a second major concern is teacher job satisfaction. In a study by the Metropolitan Life Insurance Company (Fischer, 1986), researchers found that 96 percent of former teachers are satisfied with their new occupations, while only 47 percent were satisfied with teaching. They also concluded that 58 percent claimed they miss teaching, but 83 percent said it's unlikely they'll ever return.

Thousands of studies have been reported which have sought to link a variety of variables to employee satisfaction. A substantial number of these studies have exanined the role of communication in increasing satisfaction. One conclusion that may be drawn from this research is that communication between supervisor and subordinates does have an important impact (Falcione, McCroskey \& Daly, 1977; Lashbrook, 1981; Richmond, Wagner \& McCroskey, 1983). While 
communication within an organization has been shown to be an important element impacting employee satisfaction, no single communication element has proven to be the cause of employee satisfaction or dissatisfaction across situations.

The large amount of research in the area of employee satisfaction suggests that it is of great interest to scholars, possibly because it is presumed to be linked to other concerns of organizations, such as productivity. Employee satisfaction most often is not found to be directly related to productivity, but has been tied to turnover rates and absenteeism which are major financial considerations in organizations (Richmond, Wagner \& McCroskey, 1983).

Only one instance of descriptive research was found in which communication variables were studied to determine whether or not a relationship exists between teacher perceptions of principals' leadership and teacher satisfaction on the job (Falcione, McCroskey \& Daly, 1977). Generalizations about these factors have been made, but no specific findings have been reported using the same communication variables as in this study.

One approach to organizational leadership has shown that a manager's communication can contribute to employee satisfaction. Underlying this approach is the Performance System Model (PSM) (Lashbrook, 1981). In presenting this model, Lashbrook (1981) suggests the following:

The impact a manager has on the work culture involves 
his/her communication behavior (what is talked about on the job). When that behavior is directed toward providing answers to five basic questions that employees have [Where am I going? What happens when I need help? What's in it for me? How am I doing? Why am I here?], then the manager is taking his/her proper role in a performance system. (p. 19)

So for Lashbrook, leadership is communicative effectiveness. The terms are virtually interchangeable in his model.

\section{Statement of the Problem}

The purpose of this study was to examine the communication variables used in the PSM to determine whether or not a relationship exists between a school principal's communication effectiveness and teacher satisfaction on the job. This will supplement similar research that was previously done in other organizations.

This study is an extension of a series of studies conducted by Lashbrook (1984) over a five year period. The following review of literature includes a detailed report on the results of those studies.

\section{Review of Literature}

Research in organizational communication has focused for many years on leadership communication and related concerns: innovativeness (Hurt \& Teigen, 1977); power (Rich- 
mond, McCroskey, Davis \& Koontz, 1980); communication style (Richmond \& McCroskey, 1979); discretionary and nondiscretionary leadersiip (Hunt \& Osborn, 1978); and mission, goals, feedback, rewards, and support (Lashbrook, 1981).

A number of viewpoints resulting from this research support human resources approaches to leadership. These approaches focus on employees as being capable, responsible, and creative individuals who desire to contribute to the accomplishment of worthwhile objectives. Key propositions inherent in the human resources movement are as follows:

1. Managers should trust their subordinates to perform jobs responsibly.

2. Managers should permit subordinates to participate in the making of their own jobs.

3. Managers should replace much of the mechanistic structure characteristic of most institutions with an organic approach to organization. (Goldhaber, 1983, p. 96)

Williamson (1986), editor of a book on contemporary business leadership, states in his introduction:

The overriding conclusion of these readings is that the emerging business environment is transforming the essential ordering of the assets of the business. People rather than materials, machines, facilities, or money are becoming the critical asset that must be managed or leveraged in business today. (p. 3) 


\begin{abstract}
McGregor's (1960) Theory X and Theory Y represent differing views of human nature that suggest a preferred management style. The Theory $X$ viewpoint of human nature holds that the average person has an inherent dislike of work, most people are unambitious, motivation occurs only when it relates to one's safety and security, and that people must be coerced and threatened in order to achieve organizational objectives. This style of management is often evident in organizations where people are viewed as an expense rather than an asset. Theory $Y$ claims that work is natural, creativity in solving organizational problems is utilized widely, workers seek responsibility under proper conditions, motivation occurs to help satisfy one's self-esteem and social needs, and people can be self-directed and committed. This type of management is often seen in organizations where people are the asset, and the source of creativity, diversity and adaptability. This is what Bennis (1983) calls a pull style of leadership. While researching a book on leadership, he found that an essential ingredient in organizational leadership is that the leader pulls rather than pushes people along. "A pull style of influence works by attracting and energizing people to enroll in an exciting vision of the future" (Bennis, 1983, p. 89).

This literature review concentrates on the communication of mission, goals, feedback, rewards, and support, and their relationship to personal and group satisfactions and
\end{abstract}


the work culture. Each leadership factor is conceptualized separately in the following review of literature. Additionally, the PSM will be explained in detail.

\section{$\underline{\text { Leadership }}$}

The concept of leadership has been defined in more than one hundred different ways. Among these definitions; though, there is some consensus. Essays by Fisher (1988) and Scheidel (1987) suggest that leadership can be conceptualized as communication behavior. In an article discussing the Maine Principals' Academy, Donaldson (1987) states that the academy emphasizes communication, decisionmaking, and conflict management skills as those necessary to carry out leadership functions. Additionally, after three years of research, designers of the Effective Schools Questionnaire listed four categories as dimensions of instructional leadership: resource provider, instructional resource, communicator, and visible presence (Brandt, 1987, p. 14 ).

One reason for placing so much importance on leadership in the schools is that effective leaders have been linked to effective schools. Research has confirmed what many claimed to already know; that leadership is a major contributing factor in high achieving schools (Fairman \& Clark, 1985). In conducting research for the development of the Principal Profile measure, Leithwood (1987) claims, "Effec- 
tive principals are, in a sense, the glue that holds together the many different parts of the school" (p. 65). Although there are many different methods used for training principals to become leaders, there seems to be some consensus regarding the characteristics of effective principals who run quality schools. Ford (1987) states that school leaders must "maintain positive, open communication among all concerned parties, and accept greater input from classroom teachers" (p. 218). Hallinger and Murphy (1987), authors of the Principal Instructional Management Rating Scale, claim that principals can shape the learning climate by "maintaining high visibility in order to communicate priorities and model expectations, and creating a reward system that reinforces academic achievement and productive effort" (p. 58). Furthermore, the California School Leadership Academy has developed a model for leadership. Four continuous functions outlined in the model include "analyzing behavior, feelings and values; problem solving; decision-making; and communicating" (MacAdam, 1986, p. 44). Again, communication behavior appears to be a central element.

Recent research has identified a number of properties of principals' work (Manasse, 1985; Peterson, 1982; Pitner, 1982). It has been compared to that of other managers, being composed of an enormous number of very short tasks (Mintzberg, 1973). These studies show that most of a prin- 
cipals' work occurs in face-to-face, oral interactions with others, particularly subordinates.

Manasse (1984), in a study on characteristics of effective principals who run quality schools, came to the following conclusion:

Effective principals have vision, a sense or image of the schools they wish to run. . . They establish goals and strategies and apply their time to activities which will achieve their goals. Effective principals communicate high expectations for their students as well as their staff. They demand and support quality in everything that goes on in the school. . . [They know] how to provide clear, accurate, and useful feedback to teachers. . . They help promote and sustain traditions, rituals, and ceremonies which foster a common culture and set of beliefs within the school. (pp. 153-154)

In nearly all the research examined on leadership, both in educational organizations and other organizations, communication variables were cited as being among the most important factors.

Performance System Model. The underlying rationale for the PSM is based upon several assumptions that have been tested by researchers regarding individual, group, and organizational performance.

1. Organizational performance depends upon the 
performance of individual work units.

2. Long-term work unit performance and, consequently, organizational performance depends upon work unit satisfaction.

3. Work unit satisfaction and performance are influenced by leadership performance.

4. Work unit satisfaction and performance influence leadership performance.

5. Leadership performance j.s the key to long-term change. (Wilson Learning Corp., 1985, pp. 2-3)

The PSM (see Figure 1) makes the following claims. First, organizations depend upon their work units to accomplish work at a performance level that will allow them to achieve their potential. If even one unit is performing poorly, other units may be affected in a way that hinders them from reaching their full potential. Next, high performance is often a reaction to such factors as incentives, a change in management, pressure, or a chance for promotion. While these are temporary, the PSM assumes that work unit satisfaction is one key to sustaining high performance.

Finally, leadership performance influences worker satisfaction when leaders make sure certain needs are met. These needs involve communication of five factors: mission, goals, feedback, rewards, and support. In addition, leadership performance is influenced by the level of satisfaction 
PERFORMANCE SYSTEM MODEL

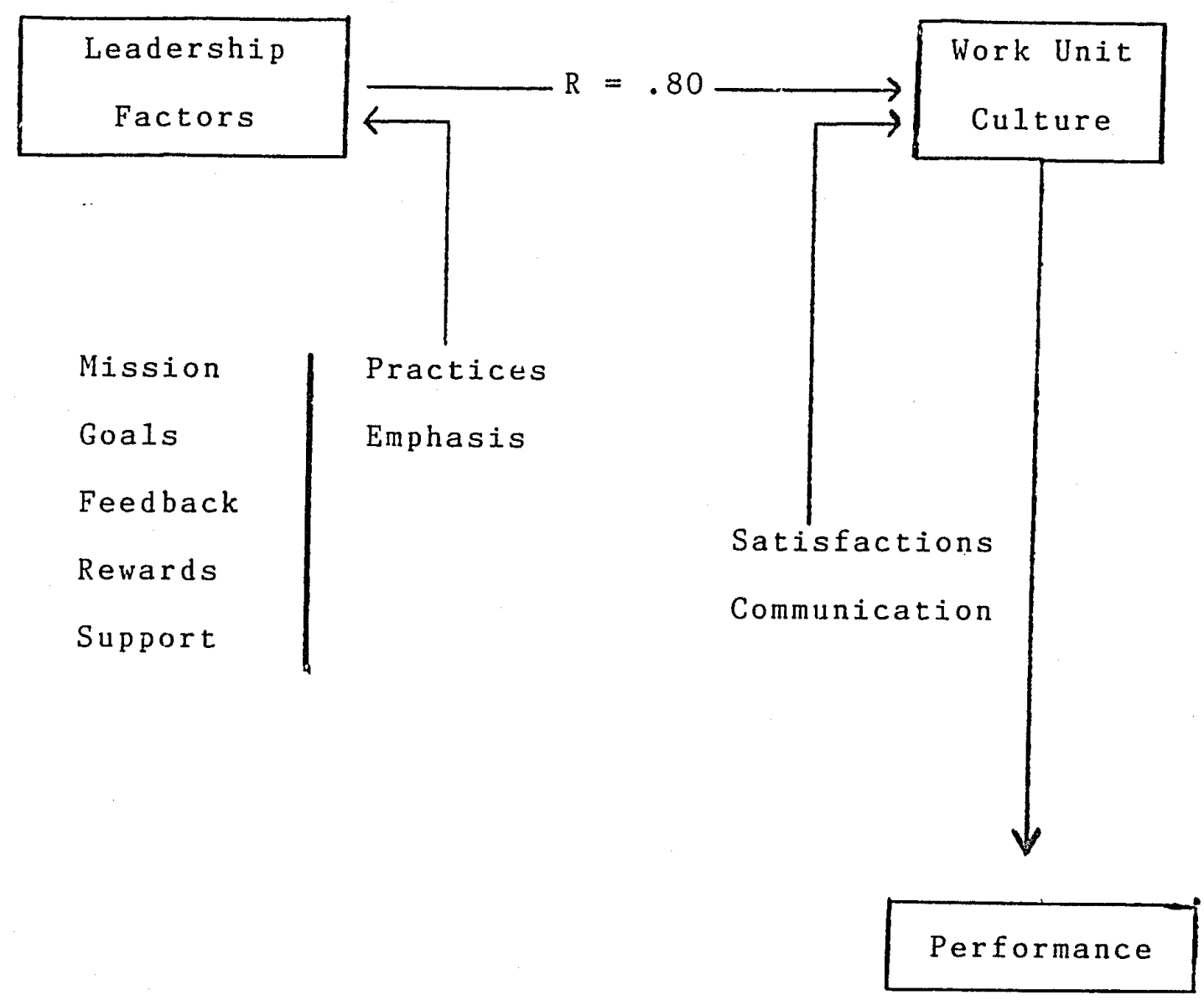

Lashbrook, W.B. (1984). Management as.a performance system. In J.N. Williamson (Ed.). The leader-manager ( .134 ).

Eden Prairie, MN: Wilson Learning Corporation. 
of a work unit. If a work unit is performing well and is satisfied, the leader can assuge that he/she is also performing well. Likert (1985) claims, "The only way to affect either employee attitudes or organizational success is to work on managerial behavior. It is a waste of effort to attack either the intervening or end-result variables directly. Until management behavior changes, nothing changes" (p. 3). Even though many might accept that managers have an influence on employee behavior, it may be an overstatement to suggest that the only road to organizational success is through managerial behavior.

Between 1981 and mid-1985, researchers used the Leadership Survey to test some of tile assumptions of the PSM on over 12,000 work units from rore than 400 organizations. Although it's difficult to make a causal connection, the results clearly showed that leadership performance and work unit satisfaction are strong $y$ and positively related in the fifteen industries surveyed. As leadership performance improves, so does work unit atisfaction.

\section{Work Cu1ture}

The term 'culture' has een linked to the study of organizations for over two decades (Herzberg, 1966, 1974; Lincoln, Hanada \& 0lson, 198:; Lashbrook, 1981). It has been used in reference to en:ire organizations as well as individual work units. In studying individual work units, 
or work cultures, a relationship has been found to exist between a manager's communication effectiveness and employee satisfaction (Lashbrook, 1984).

Work culture consists of common norms regarding the organization or work groups against which behavior can be judged. The concept of work culture is closely related to the concepts of communication environment and climate. For example, Borden (1977) defines environment as the context in which communication takes place, and notes that the cultural aspect of this context is concerned with one's attitudinal frame of reference.

For the purpose of this thesis, the term 'culture' applies to the individual elementary school faculties within a school district. Prior research involved asking employees which unit within their organization most influences their productivity (Lashbrook, 1979, 1980). The most cominon unit mentioned was composed of "themselves, their job, their coworkers, their manager, and their manager's manager." However, subsequent studies led researchers to drop the manager's manager as a work unit parameter due to infrequent interaction between that person and the subordinates of a given manager.

Two categories of perceptions are related to work unit culture. The first category is "levels of satisfaction," the second is "what is talked about on the job" (Lashbrook, 1984). Lashbrook (1981) states, "A positive work culture, 
then, is characterized by members of a work unit perceiving themselves to be satisfied with themselves, their job, their co-workers, and the way they are managed with respect to communication about mission, goals, feedback, rewards, and support" (p. 6).

Work Unit Satisfaction

Employee satisfaction with work has been defined as a general positive affective orientation toward an employing organization and one's roles and relationship within it (Lincoln, Hanada \& 0lson, 1981). Factors developed to represent satisfaction include such items as pay, promotion, supervisor, job, self, and co-workers (Smith, Kendall \& Hulin, 1969).

Locke (1976) estimates that more than 3,300 studies on job satisfaction have been published. These studies include such variables as communication apprehension (Falcione, McCroskey \& Daly, 1977), self-esteem (Wylie, 1961), permitting employees to communicate in the decision-making process (Falcione, 1974), mission and goals (Lashbrook, 1981), feedback (Herzberg, 1966; Lawler, 1974; Kerr, 1975; Yankelovich \& Immerwahr, 1983), and support (Barnes, 1981; Kanter, 1983). Furthermore, research has found that employees who have positive perceptions of the communication of their supervisors are significantly more satisfied. Falcione, McCroskey and Daly (1977) report substantial correlations 
between employee satisfaction and employee's perceptions of their supervisor's listening ability, the level of understanding the supervisor shows, and the general quality of the supervisor's communication.

Only one study was found in which communication variables were used to determine the relationship between perceptions of a principals' leadership effectiveness and teacher satisfaction on the job. In that study, Falcione et al. (1977) administered nine separate measures to 189 elementary and secondary school teachers. Included were measures for communication quality and job satisfaction. Job satisfaction was operationalized with the use of the Job Descriptive Index (Smith, Kendall \& Hulin, 1969). The researchers concluded that a teacher's satisfaction with his/her supervisor appears to be most closely associated with the teacher's perceptions of the supervisor's communication behavior (perceived listening, understanding, and quality) (p. 373). That study yielded data of considerable value for understanding and predicting subordinate satisfaction in organizations because it showed that both subordinate perceptions of their supervisors and subordinate's own self concepts are related to satisfaction. This study adds additional information to the research by Falcione et al. (1977) by looking at whether or not we can predict teacher satisfaction as a result of studying five other communication variables not included in their research. 
In a separate study, lise of the Management Communication Style Scale resulted $z$ the findings that employees who perceive their supervinors as using a more employeecentered management communcation style are more satisfied than employees who perceivt their bosses as using a more boss-centered management c munication style (Richmond, McCroskey, Davis \& Koontz, 1980). Similarly, use of the Leadership Survey (Wilson earning Corporation, 1981) indicates that employees who perceive their supervisors as using the appropriate app ication and amount of time in communicating mission, go.ls, feedback, rewards, and support, perceive themselves as be ng more satisfied with themselves, their job, their co-workes, and the ways they are managed. Thus, employee perceptions of their supervisors play a major role in their level of satisfaction.

In this study, work unit satisfaction is conceptualized as the personal and perceived group satisfaction that members of a work unit experience. "The perceived level of personal satisfaction of work unit members includes their level of comfort with themselves on the job, the job itself, their co-workers, and the ways they are managed" (Wilson Learning Corp., 1985, p. 9). The perceived level of group satisfaction is the extent to which an individual believes that the others in the work unit are likely to describe their work unit and organization in a positive manner. "Specific factors include mission (Why am I here?), 
goals (Where am I going?), feedback (How am I doing?), rewards (What's in it for me?), and support (What happens when I need help?)" (Wilson Learning Corp., 1985, p. 9). Results of the research by Wilson Learning Corporation as of 1984 showed that, for the work units under investigation, the best predictor of work unit satisfaction was manager feedback, followed respectively by rewards, support, mission, and goals.

Mission

According to Lashbrook and colleagues' work, the first of five communication content areas that are important is "mission." Feeling a sense of mission on the job is important because it provides a context for understanding one's role and making sense of the tasks one is required to perform (Wilson Learning Corp., 1985). Peters and Waterman (1982) found in their study of excellent companies that each had a chief executive officer who had articulated a mission that used only a few words to summarize what was unique and special about the company; what the company stood for. For example, AT\&T has as it's motto "Universal service." Hewlett Packard's is "Innovative people at all levels." General Electric follows the theme "Progress is our most important product." IBM holds a statement of "Customer service," and Du Pont's belief is "Better things for better living through chemistry." 
One major purpose of a clearly communicated mission is that it can be a vehicle for change. Bradford and Cohen (1984) did a case study of a major bank that was experiencing low morale and lower productivity than had been forecast. As a result of that study they concluded, "If the manager can articulate and gain member commitment to a vision of the future, the mission then serves as an important stimulus for change toward excellence" (p. 297). Here, mission is conceptualized as "a work unit's perception of the degree to which the work unit has a sense of purpose or reason for being" (Wilson Learning Corp., 1985, p. 14). It also includes the degree to which a work unit feels it is making a significant contribution to both the work unit and the organization's success. A work unit's understanding of the needs of its clients is also indicated by mission. The PSM is based on the assumption that it is critical for individuals to have an effectively communicated vision of what the organization is trying to accomplish, and to understand how their particular job contributes to that mission.

The concept of mission has special significance in the field of education. Because those making the critical decisions that affect education's future are often not educators, the field is at the mercy of every new fad and shifting societal emphasis.

The first of three dimensions of instructional leader- 
ship on the Principal Instructional Leadership Rating Scale (Hallinger \& Murphy, 1987) is "defining the school mission." Research conducted by Hallinger and Murphy (1987) in preparation for designing the measures suggests that, "Instructional leaders have a clear vision of what the school is trying to accomplish. Defining the mission entails leading the staff in developing schoolwide goals and communicating them to the entire school community" (p. 57).

No study was found in which the effect of communication on mission had been tested in educational organizations. However, there is evidence that a mission statement makes a difference in other industries. The value of employees knowing an organization's mission and their relationship to it has been positively related to employee satisfaction. Keller (1975) has shown that lower satisfaction among employees can result when they receive conflicting or vague messages regarding why the organization is in existence and what it is trying to accomplish.

Phillips and Kennedy (1980) developed the theory of Shared Values as a result of extensive research in successful organizations such as IBM, Du Pont, AT\&T, and Dana. They claim that a company's mission, or shared values, defines the fundamental character of the organization. The shared values create a special sense of identity for employees, giving meaning to work as something more than earning a living. 
A mission stateme:.t seeks to answer the question "why am I here." When emplijyees have a clear understanding of that, they can begin to concentrate on their work unit's goals.

Goals

Not long ago, an irganization's goals were simple and few. The problem of managing goals was a matter of their specification, their communication, and the resources to achieve them (Williamson, 1984). Today, goals are often used to help resolve conflict and in decision-making situations (Likert \& Likirt, 1976).

Goals refers to "the clarity about the results toward which efforts are directed" (Wilson Learning Corp., 1985 , p. 16). The question "where am I going" is often asked by employees who seek to determine the degree of understanding they have for the goals of their work unit.

Ultimately, the purpose of goal setting is to gain commitment to individual and work unit objectives. "For commitment to occur, goals must be clear and understandable, specific and measurable, realistic and attainable, and relevant and meaningful" (Wilson Learning Corp., 1985, p. 16).

In a study on goal-setting attributes and their relationship to job sarisfaction (Arvey \& DeWhirst, 1976), goal clarity and planning was found to lead to increased employee satisfaction. Furthermore, Steers (1976) studied 
factors affecting job attitude in goal-setting environments and determined that participation in goal-setting leads to increased employee satisfaction as well. The PSM also assumes a relationship between communication of goals and employee satisfaction, and points to the need for leaders clearly to communicate goals and provide an environment in which commonly held goals can be met. When this is established, communication and action regarding feedback, rewards, and support can begin.

$\underline{\text { Feedback }}$

Simply stated, feedback is information about progress toward the accomplishment of goals. A considerable amount of research exists that establishes a positive relationship between feedback and employee satisfaction (Greene, 1977; Pedalino \& Gamboa, 1974; Sims \& Szilagyi, 1975; Timbers, 1974). While studying leader reward behavior and employee satisfaction, Sims and Szilagyi (1975) found that employees are more satisfied and report being more productive when they receive information based upon objective evaluations of their performance. Additionally, the way in which supervisors provide feedback has also been related to employee satisfaction (Arvey \& DeWhirst, 1976).

Feedback seeks to answer the question "how am I doing." The PSM makes the following assumptions about feedback:

1. The value of feedback depends upon its usefulness, 
accuracy, relevance, and the credibility of its giver.

2. Feedback is related to goals because it enhances the effectiveness of goal setting by providing information needed to modify behavior in order to achieve those goals.

3. Feedback is related to rewards in that it is an. indication about how close one is to receiving reinforcement.

4. Employees desire frequent feedback to know they are making progress.

5. When employees are performing well, they want to know that others recognize their progress. (Lashbrook, 1981, pp. 13-14)

In an empirical examination of perceived differences and similarities between managers and subordinates concerning job satisfaction, Habegger and Lashbrook (1981) found that a problem can occur in organizations when a supervisor fails to give feedback. They concluded that when a subordinate does not receive feedback about how he/she is doing on the job, it will be invented. They also claim that invented feedback will often be unrealistic and distorted. Therefore, a leader needs to provide feedback in sufficient quantities so it will not be made up by his/her employee. Michael (1976), whose research has been undertaken mostly in the public sector, states, "It is through information 
feedback that a system evaluates where it is in terms of where it intends to go" (p. 385).

\section{$\underline{\text { Rewards }}$}

Rewards are consequences that maintain or improve performance. The question "what's in it for me" seeks to determine what an employee finds to be rewarding.

Research shows that when there is communication between a manager and an employee, the result is often an increase in employee satisfaction (Greene, 1977; Herzberg, 1968; Scanlan, 1976; Yankelovich \& Immerwahr, 1983). Herzberg (1968) surveyed 1,685 employees from a variety of pub1 ic and private-sector organizations to determine factors that are involved in causing job satisfaction and job dissatisfaction. Results showed that of all the factors contributing to job satisfaction, 81 percent were motivators such as achievement, recognition, and advancement. In another study (Yankelovich \& Immerwahr, 1983), workers were asked what features would jmprove their jobs. They mentioned "recognition for good work" 70 percent of the time, and "a good chance for advancement" 65 percent of the time. After conducting research on rewards in a manufacturing organization and an insurance firm, Kerr (1975) claims there is a tendency in organizations to profess a desire to accomplish certain objectives while structuring and sustaining a reward system that pays off behavior that is 
directed somewhere 2 lse. As a result, some experts (e.g., Herzberg, 1968; La:Ler, 1974; Yankelovich \& Immerwahr, 1983) have begun to point toward a new direction in the theory of manaing rewards - one that places less emphasis on the reinforcement qualities of extrinsic rewards and more on the inherent motivitional qualities that the content of the work itself ca! provide.

Another aspec: of rewards is equity. An examination of manager and subordinate perceptions regarding job satisfaction (Habegger \& Lashbrook, 1981) led to the finding that most subordin.tes cannot tolerate a disproportionate use of rewards. A: a result, the researchers suggest that managers and suborinates need to communicate about what is perceived as being fair and consistent reinforcement.

The PSM assumes that rewards, to be effective, should be immediate, linked to performance, and adapted to individual needs. Effective rewards are highly individualized. To discover what an individual finds rewarding, a manager needs to ask, try different approaches, and observe what works (Wilson Learning Corp., 1985). A manager needs to provide an environment (a positive work culture) in which people can reinforce each other for doing good work.

\section{Support}

In the past, managers could assume that providing direct help to their subordinates satisfied their responsi- 
bilities regarding support. Today, the changing context of businesses requires a reexamination of support as a vital management function (Williamson, 1984).

The meaning of the question "What happens when I need help?" has taken on important new dimensions. This question seeks to determine both the knowledge level and the amount of trust that exists within a work unit. Employees need to know that when something goes wrong on the job, they can legitimately seek help from someone else (Scanlan, 1976). The source of help today is no longer solely the manager, it is wherever it happens to be.

Support is closely related to trust. Driscoll (1973) completed a study in which he sought to determine whether or not trust was a predictor of job satisfaction. His study suggests that employee satisfaction in organizations is determined more by the degree of trust present than by levels of participation in decision-making. According to Barnes (1981), the manager is the key factor in determining a work unit's pattern of behavior related to trust.

Management support has been linked to both employee performance and satisfaction (Hunt \& Hi11, 1977; Scanlan, 1976; Seashore \& Bowers, 1977). Specifically, supportive supervisory characteristics (Scanlan, 1976), have been positively related to increased employee satisfaction. Supportive behavior implies an openness in communication channels and availability of managers for interpersonal 
communication (Koehler, Anatol \& Applbaum, 1976).

The PSM assumes that support often takes the form of advice or education. It is the help individuals receive in overcoming performance obstacles. Occasionally, support is required from other parts of an organization. Without support, a person may be unable to improve performance. Support also demonstrates that a manager cares and is committed to helping his/her subordinates succeed.

Practices and Emphasis

The Leadership Survey (LS) measures the five leadership factors: mission, goals, feedback, rewards, and support, in terms of practices and emphasis. "Practices" refers to a work unit's perception of the appropriateness of the way in which each factor is applied or implemented in the work unit. "Emphasis" is a measure of the perceived appropriateness of the time a manager spends on each factor. "Generally, the more time managers spend on a factor, the more effective they will be" (Wilson Learning Corp., 1985 , p. 13$)$.

A relationship between practices and emphasis for the 432 organizations surveyed has been determined. For mission and goals, increased emphasis improves practices only slight1y. Spending more time on these two factors may help, but it is probably more important to focus on how the time is spent. For feedback, rewards, and support, increased 
emphasis appears to improve practices dramatically. While it is useful to examine how time is spent on these three factors, spending sufficient time is critical.

\section{Statement of the Research Questions}

Again, this study is an attempt to determine whether or not a relationship exists between a school principal's. communication effectiveness and teacher satisfaction on the job. Careful consideration of the model constituted the development of the following research questions:

1. Is there a relationship between a school principal's communication of mission, goals, feedback, rewards, and support as perceived by teachers, and work unit culture (a combination of personal and group satisfactions)?

2. Are there differences among the various teacher demographic groups (county, age, sex, number of years as a teacher) in their perceptions of school principal's communication and/or job satisfaction?

3. Is there a difference in teachers' perceptions of job satisfaction and/or school principals' communication in Santa Cruz and Santa Clara Counties in comparison to the average perceptions of managers of other organizations in the data base? 


\section{Rationale}

This study makes several unique contributions that advance one's understanding of the theories of organizational communication by addressing practical and theoretical concerns.

The first contribution of this study is that it allows educational organizations to make use of a predictive model for employee satisfaction. It is important to reiterate that only one other study was found in which communication variables were used to determine the relationship between perceptions of a principal's leadership effectiveness and teacher satisfaction on the job (Falcione et a1., 1977). The authors of that study concluded that subordinate satisfaction in organizations can be predicted by studying subordinate perceptions of their supervisor's communication behavior. It is clear that more empirical studies of this type need to be done in educational organizations in order to see how they might differ from other types of organizations.

The second contribution of this study is that it begins the process of establishing norms for educational organizations for the PSM. The predictive efficacy of the PSM has been shown in other organizations. As previously stated, researchers used the Leadership Survey to study PSM variables on over 12,000 work units. However, no teachers were included in the survey and no education norms 
have been established to date for the PSM.

Establishing norms for educational organizations is helpful because these norms allow comparisons with norms of fifteen other types of organizations. Norms are also useful in making comparisons between local school systems in Santa Cruz and Santa Clara Counties. They can help principals increase their understanding as to how their communication behavior is perceived by teachers.

The third contribution of this study is that it supports the claim of many researchers that leadership is a communication concern. An extensive review of both education and communication literature suggests that communication variables are among the most important characteristics of leadership. This is precisely why the PSM was the model chosen to be studied in this thesis. It defines leadership as a communication concern, with five communication variables (mission, goals, feedback, rewards, and support) as its leadership factors.

Finally, the contribution of this study is that it addresses an important area of organizational communication theory: job satisfaction. Communication within an organization has been shown to be an important element impacting employee satisfaction (Richmond, Wagner \& McCroskey, 1983).

This concern is particularly evident in educational organizations because of the growing dissatisfaction among 
teachers. During the past two years, researchers have been exploring the area of teacher satisfaction on the job and a connection between school leadership and job satisfaction has been assumed to exist (Fischer, 1987; Heyns, 1988). Poor working conditions, which included supervision, was the reason 60 percent of former teachers gave for leaving the profession in a 1986 study by Metropolitan Life Insurance Company. In an exhaustive study by Heyns (1988) on teacher attrition, teacher shortages were found to occur in the same sorts of schools that report fairly high levels of teacher dissatisfaction. She states that, "Professional working conditions are widely viewed as the single most important reason for high rates of teacher attrition" (p. 29). However, the connection between principals' communication behavior and job satisfaction in the schools hasn't been adequately examined. It may be that teachers are autonomous enough in their work that communication factors have little influence on satisfaction. It also may be that teachers communicate more often with their peers than with their principals. Perhaps the constant communication between student/teacher and parent/teacher has a greater influence on satisfaction. Studying PSM variables in the educational setting provides concrete data on which to base such assumptions. 


\section{CHAPTER II}

\section{Methods}

This chapter describes the methods that were employed to evaluate the relationship between a school principal's communication effectiveness and work unit culture. In general, this study was a survey of teacher perceptions regarding leadership communication and personal and group satisfaction. Specifically, the following subjects are discussed: the survey instrument, the respondents, the procedure, and the methods of data analysis.

\section{The Survey Instrument}

The measuring instrument used in this study was developed in 1981 by Wilson Learning Corporation. First known as the Management Performance Inventory, it is now the Leadership Survey (see Appendix A). It asks respondents to rate their immediate supervisor's effectiveness in communicating five factors: mission, goals, feedback, rewards, and support. Respondents are also asked to supply ratings of group and personal satisfaction on the job. Together, these satisfaction ratings represent a rating of "work unit culture."

For this study, the following words were changed on the LS to make it more appropriate for use by teachers: "manager/supervisor" to "principal," "organization" to 
"school," "work unit" to "faculty," and "upper management" to "other administrators in the district."

Two emphasis questions and four practice questions are included for each of the five communication variables (see Appendix B). Six group satisfaction and four personal satisfaction questions are also included. Employee satisfaction items ask respondents for satisfaction ratings regarding themselves, their job, their co-workers, and the way in which they are managed. All questions are presented on an eleven-point scale. Responses are end-point anchored with descriptive phrases. Forty questions are included in the instrument.

By August, 1985, over 75,000 individuals had completed the LS for Wilson Learning Corporation (1985). These people represented 12,433 work units and 432 organizations. Tables 1 and 2, taken from Wilson Learning Corporation's Leadership Growth Opportunities (1985, pp $26-27$ ), show comparative information for each of the thirteen measures provided by the survey for fifteen different industries. Although education norms could possibly be included in the service industry category, a telephone interview with Lashbrook verified that no schools were included in the survey norms. The LS has been found to be statistically adequate for testing the Performance System Model (Lashbrook, 1981) (see Table 3$)$. The various indices used to measure a subordinate's perceptions of a manager's use of mission, goals, 


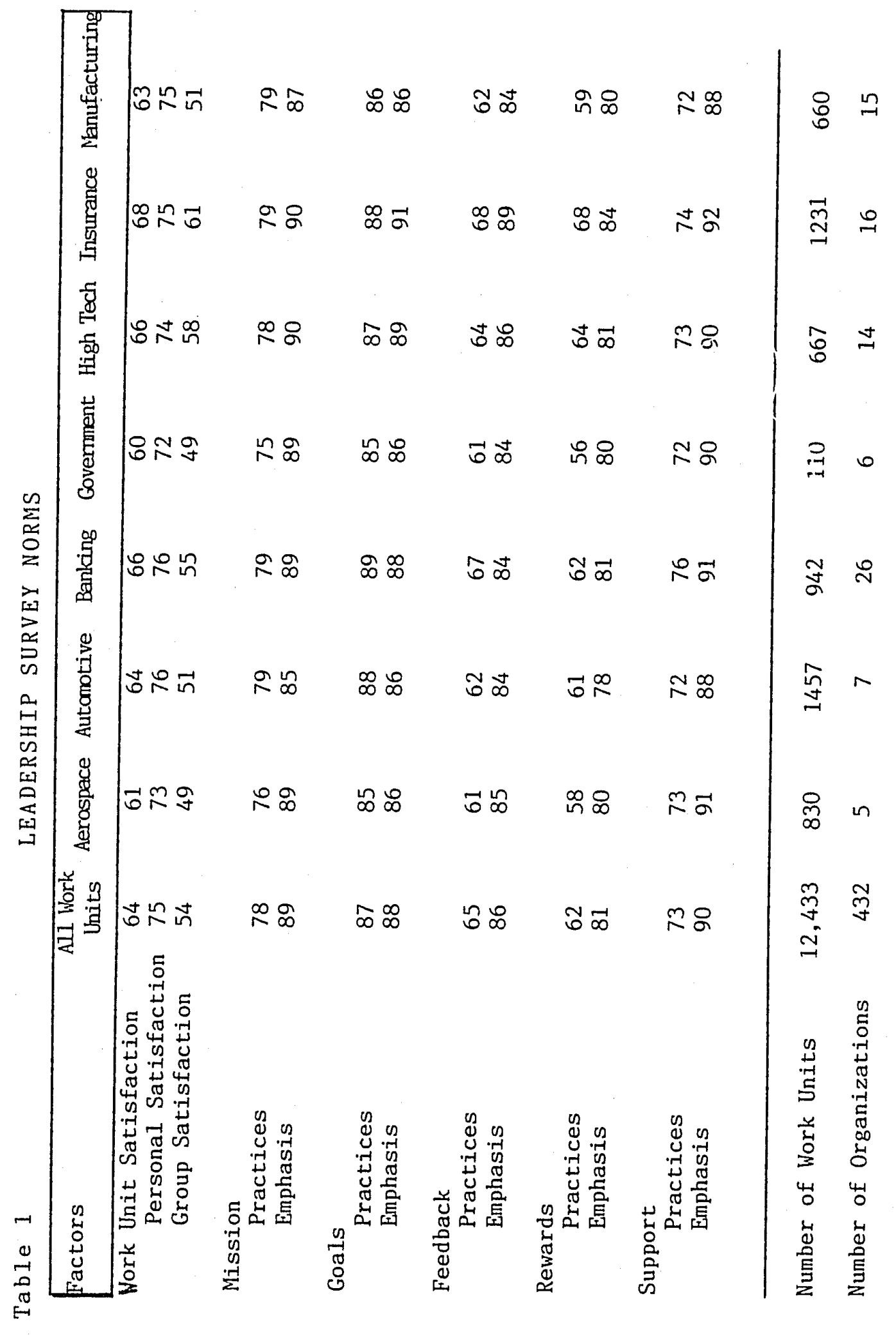




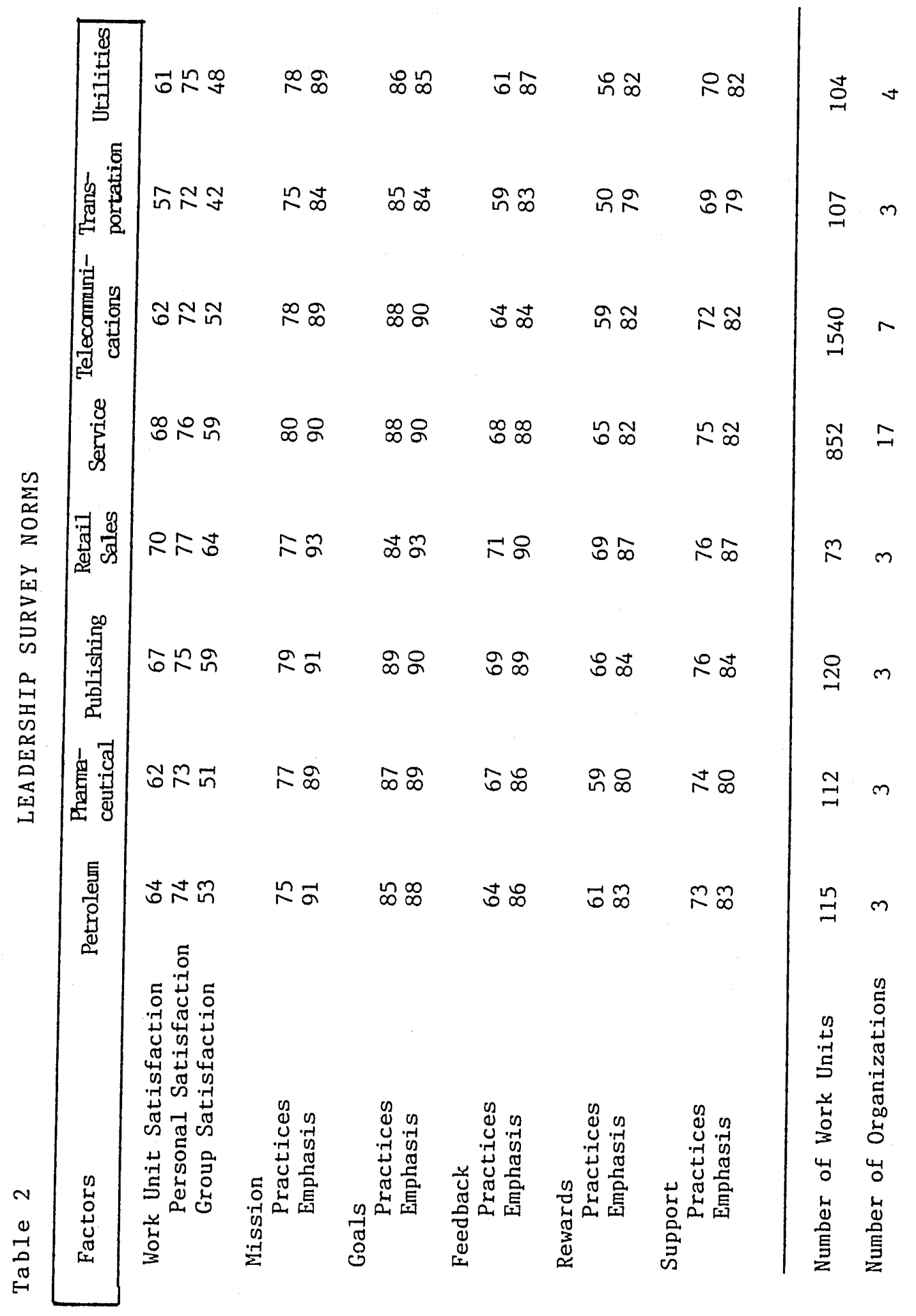


Table 3

Reliability estimates for the Leadership Survey Measures June 1,1981

\begin{tabular}{lcccc}
\hline MEASURES & ALPHA & SPLIT-HALF & GUTTMAN & INTRACLASS(5) \\
\hline Mission & .79 & .71 & .70 & .78 \\
Goals & .78 & .71 & .71 & .78 \\
Feedback & .83 & .72 & .71 & .75 \\
Rewards & .89 & .88 & .88 & .80 \\
Support & .81 & .78 & .78 & .72 \\
Satisfactions & .76 & .71 & .71 & .81 \\
\hline
\end{tabular}


feedback, rewards, and support have alpha reliabilities ranging from .78 to .89 from a total data base that exceeded 2,500 , and a standard error of measurement less than 1.0 . The measure of perceptions of the work culture by subordinates has an alpha reliability of .84 and a standard error of less than 1.0. A canonical correlation of .80 was found to exist among the measures of managerial effectiveness and subordinate perceptions of the work culture.

The LS appears to be a superior measure of job satisfaction compared to the alternatives. The Job Descriptive Index (Smith, Kendall \& Hulin, 1969), a measure used often by communication researchers, has reliabilities ranging from .80 to .92 However, these reliabilities only hold true when fourteen items with item-total correlation and face-validity problems are deleted from the 72 item measure. The LS, on the other hand, has maintained highly stable reliabilities as well as standard errors of measurement. The reliability estimates for the LS also correlate with other well-known measures of communication and job satisfaction, which gives us some indication of construct validity. First, the LS has face validity, or appears to measure what it is intended to measure as "supported by the informed judgments of people trained in management theory" (Wilson Learning Corp., 1981b, p.87). Secondly, the scale contained on the LS was selected from empirical research done on managerial appropriateness, job satisfaction, and 
work climate. Thirdly, as of 1981 , the LS had undergone three revisions, each based on pilot tests aimed at refining the scales in the instrument. Fourth, the validation of the PSM gives us an indication of the construct validity of the survey j.tself. In all instances, the pilot data supported the basic model upon which the LS is based. The data consistently upheld an $R_{c}=.80+$ relationship between. the five leadership factors (mission, goals, feedback, rewards, and support) and work culture (a combination of personal and group satisfaction scores.)

In addition to the LS, demographic information was collected from the respondents. This included age, sex, number of years as a teacher, and number of years serving under the principal being evaluated.

\section{The Respondents}

The respondents for this study were teachers from pubIic elementary schools within Santa Cruz and Santa Clara Counties. Two-hundred-fifty-seven teachers were randomly chosen and asked to respond to the LS. A total of 133 usable surveys were returned and constitute the data base for this study. Each teacher represented a different school and reacted to the communication effectiveness of a different principal. The purpose, of course, was not to report the evaluations by a teacher of individual principals, but to pool these evaluations to get a sense of the larger picture. 
All participants had the LS mailed to them at their school sites. Envelopes were addressed to Second Grade Teacher, Fifth Grade Teacher, and so on. The grade specified was randomly assigned for each school.

\section{The Procedure}

The LS was administered to participating teachers during 0ctober of 1988. The name of the grade level to which each respondent was currently assigned, along with the name of his/her school, was listed and given a unique number. Corresponding numbers were placed on the questionnaires. Such a system allowed the respondents to remain anonymous and enabled the researcher to keep track of which schools had a participant complete and return the forms. Questionnaires, including a cover letter (see Appendix A), were individually mailed to each participating teacher at his/her school site. The procedure involved each teacher completing the questionnaire at his/her convenience and then mailing the form directly to the researcher in the envelope provided. The envelopes were preaddressed and stamped.

Forms were immediately scored as they were returned to the researcher. Two weeks after the questionnaires were mailed, a second mailing was directed to respondents who had not returned the forms. Six weeks after the initial mailing, all data were entered into a computer with 52 
percent of the forms having been returned.

As stated previously, two emphasis questions and four practice questions are included in the LS for each of the five predictor variables. For the purpose of this study, however, emphasis questions were eliminated from analysis because the researcher was examining perceptions of communication, not perceptions of time. Therefore, on $1 y$ practice questions were included in the statistical analysis for the predictor variables.

\section{The Methods of Data Analysis}

In order to answer the first research question (Is there a relationship between a school principal's communication of mission, goals, feedback, rewards, and support as perceived by teachers, and work unit culture?), a canonical correlation analysis was used. The predictor variables were identified as mission, goals, feedback, rewards, and support. Criterion variables were personal satisfaction and group satisfaction (the combination of which constituted work unit culture). A canonical correlation allowed the researcher to determine the relationship of the combination of predictor variables with the combination of criterion variables. This answers the research question and indicates whether or not the Lashbrook model is applicable to the educational organizations being studied. Descriptive statistics were also calculated for all variables. 
The second question (Are there differences among the various teacher demographic groups in their perceptions of school principals' communication and/or job satisfaction?) was answered through the use of two separate procedures. The first procedure involved t-tests for independent samples whereby tests of mean differences between Santa Cruz and Santa Clara Counties, and males and females, were performed for both predictor and criterion variables. The second procedure involved a one-way analysis of variance for culture by age.

The third question (Is there a difference in teachers' perceptions of job satisfaction and/or school principals' communication in Santa Cruz and Santa Clara Couities in comparison to the average perceptions of managers of other organizations in the data base?) was answered through the use of a t-test for independent samples.

Data were analyzed using the Statistical Package for the Social Sciences (SPSS) on the CYBER computer system at San Jose State University. 
CHAPTER III

Results

The previous chapter described the methods for statistical analysis used in this study. This chapter reports the results of the statistical analysis on data collected by administration of the LS to teachers from Santa Cruz and Santa Clara County schools. Results of the analysis are organized into two sections: preliminary analysis and primary analysis. The purpose of the preliminary analysis is to describe the respondent pool. The primary analysis reports findings regarding the relationship between predictor variables (mission, goals, feedback, rewards, and support), and criterion variables (personal and group satisfaction). Also included are comparisons of education findings described in this study to findings from other types of organizations previously reported from Lashbrook's (1984) studies:

\section{Preliminary Analysis}

A total of 133 elementary school teachers were included in the respondent pool, representing thirty-three school districts. Demographic data for the respondents are listed in Table 4. The difference in the number of respondents between Santa Cruz and Santa Clara Counties is simply a reflection of the population of each county, 
Table 4

Demographic Data for Respondent Pool

Category Number of Teachers

\section{County}

$\begin{array}{lr}\text { Santa Cruz } & 21 \\ \text { Santa Clara } & 112\end{array}$

Age

$$
\begin{aligned}
& 21-30 \\
& 31-40 \\
& 41-50 \\
& 51-63
\end{aligned}
$$$$
12
$$$$
29
$$$$
63
$$

Sex

Female

Male

Years of Experience

$1-5$

21

$6-15$

28

$16-25$

58

$26-42$ 
not the degree of willingness among teachers to participate in the study. Specifically, 60 percent of teachers in Santa Cruz County who were asked to respond to the survey did so, as did approximately 44 percent from Santa Clara County. Total rate of return was approximately 52 percent. The demographic data also show 56 percent of the respondents to be between the ages of 41-50, and 51 percent to have taught school for 16-25 years.

Descriptive data for both predictor and criterion variables are displayed in Table 5. As noted in Chapter II, LS emphasis questions (measures of the perceived appropriateness of the time a manager spends on each factor) were eliminated from the analysis and only practice questions (measures of the perceived effectiveness in communicating each factor) were included in the statistical analysis for the predictor variables. Possible points on the LS totaled 40 for each predictor variable, 60 for group satisfaction, and 40 for personal satisfaction. Group and personal satisfaction scores were changed to percentages so they could be weighted equally to arrive at a score for culture.

In general, teachers rated their principals highest on their communication of mission and goals, and lowest on their communication of feedback and rewards. Additionally, preliminary analysis indicates that teachers perceive their work groups as being less satisfied than they are 
Table 5

Leadership Survey Descriptive Data

\begin{tabular}{lccc}
\hline Variable & Mean & S.D. & Range \\
\hline Mission & 32.053 & 5.614 & 10 to 40 \\
Goals & 32.774 & 5.534 & 11 to 40 \\
Feedback & 25.376 & 11.358 & 0 to 40 \\
Rewards & 24.316 & 9.552 & 1 to 40 \\
Support & 29.759 & 8.510 & 6 to 40 \\
Group Sat & 60.842 & 25.349 & 5 to 100 \\
Personal Sat & 79.173 & 14.974 & 33 to 100 \\
Culture & 140.015 & 37.974 & 41 to 200 \\
& & & \\
\hline
\end{tabular}


with themselves personally.

\section{Primary Analysis}

In order to examine the first research question, which asks if there is a relationship between a principal's communication effectiveness and teacher satisfaction on the job, a canonical correlation analysis was employed. Results of the analysis are shown in Tables 6 and 7 .

A single significant canonical correlation was produced between the predictor set of variables and the criterion set of variables $\left(\underline{R}_{c}=.86, \underline{p}(.001)\right.$. The eigenvalue $\left(\underline{R}_{c}{ }^{2}\right)$ indicates that these two sets of variables have 74 percent shared variance.

According to Table 6 , feedback appears to be the best predictor of culture, accounting for 67 percent of the variance in culture with a correlation of .82. Feedback also correlates significantly with support, again having a shared variance of 67 percent. Correlation coefficients for support (.76) and rewards (.73) suggest that these two variables are the second and third best predictors of culture. Mission and goals appear to be the least likely predictors of culture among teachers in the respondent pool. Canonical coefficients displayed in Table 7 also suggest that feedback is the best predictor of culture, while goals appears to be the least likely predictor.

The second research question, which asks if there 
Table 6

Correlation Coefficients

\begin{tabular}{lcccccccc}
\hline \hline & Mission & Goals & Feedback & Rewards & Support & Group Sat & Per Sat & Culture \\
\hline Nission & 1.00000 & & & & & & & \\
Coals & .44364 & 1.00000 & & & & & & \\
Feedback & .42776 & .46597 & 1.00000 & & & & & \\
Rewards & .38225 & .40019 & .71735 & 1.00000 & & & \\
Support & .43233 & .51498 & .81670 & .65612 & 1.00000 & & \\
Group Sat & .45083 & .46970 & .80978 & .69677 & .75031 & 1.00000 & & \\
Per Sat & .46847 & .39299 & .71611 & .66397 & .65103 & .75776 & 1.00000 & \\
Culture & .48547 & .46851 & .82293 & .72693 & .75757 & .96633 & .90015 & 1.00000 \\
& & & & & & & & \\
\hline
\end{tabular}


Table 7

Canonical Correlation Analysis

\begin{tabular}{cccccc}
\hline Eigenvalue & $\begin{array}{c}\text { Canonical } \\
\text { Correlation }\end{array}$ & Wilk's Lambda & Chi-Square & df & $\underline{p}$ \\
.74242 & .86164 & .24967 & 177.56837 & 10 & $\mathrm{p}<.05$ \\
\hline
\end{tabular}

Canonical Coefficients

Predictor Set

Mission $\quad .13075$

Goals $\quad .03051$

Feedback $\quad .53174$

Rewards $\quad .26769$

Support $\quad .19946$
Criterion Set

Group Sat $\quad .71664$

Personal Sat .34089 
are differences among the various teacher demographic groups (county, age, sex) in their perceptions of school principal's communication and/or job satisfaction, was examined through the use of $\underline{t}$-tests for independent samples and a one-way analysis of variance. Tables 8 and 9 report the results of t-tests of mean differences between Santa Cruz and Santa Clara Counties, and females and males, for both predictor and criterion variables.

Results of the t-tests for county indicate that there is no significant difference between teachers in Santa Cruz and Santa Clara Counties in their perceptions of principal communication effectiveness or job satisfaction (no p-values exceeded .05). Additionally, no significant differences were found between sexes for any of the predictor or criterion variables.

Table 10 reports the results of a one-way analysis of variance for culture by age. This test did not indicate significant differences between any two groups at the .05 level.

After analyzing all the data obtained for the eductional organizations included in this study, further analysis was performed to compare those results with data obtained for thirteen other types of organizations from previous studies by Lashbrook (1984). These comparisons were done in order to answer the third research question (Is there a difference in teachers' perceptions of job 
Table 8

T-Tests for County

\begin{tabular}{|c|c|c|c|c|c|c|}
\hline Variable & & Mean & $\underline{\mathrm{SD}}$ & $\underline{t}$ & $\underline{d f}$ & $\underline{\mathrm{p}}$ \\
\hline \multicolumn{7}{|l|}{ Mission } \\
\hline Santa & Cruz Co & 32.1 .4 & 5.77 & \multirow{2}{*}{.08} & \multirow{2}{*}{27.55} & \multirow{2}{*}{.938} \\
\hline Santa & Clara Co & 32.04 & 5.61 & & & \\
\hline \multicolumn{7}{|l|}{ Goals } \\
\hline Santa & Cruz Co & 33.10 & 5.44 & \multirow{2}{*}{.29} & \multirow{2}{*}{28.45} & \multirow{2}{*}{.771} \\
\hline Santa & Clara Co & 32.71 & 5.57 & & & \\
\hline \multicolumn{7}{|l|}{ Feedback } \\
\hline Santa & Cruz Co & 25.14 & 11.77 & \multirow{2}{*}{-.10} & \multirow{2}{*}{27.41} & \multirow{2}{*}{.922} \\
\hline Santa & Clara Co & 25.42 & 11.33 & & & \\
\hline \multicolumn{7}{|l|}{ Rewards } \\
\hline Santa & Cruz Co & 24.33 & 7.99 & \multirow{2}{*}{.01} & \multirow{2}{*}{32.54} & \multirow{2}{*}{.992} \\
\hline Santa & Clara Co & 24.31 & 9.85 & & & \\
\hline \multicolumn{7}{|l|}{ Support } \\
\hline Santa & Cruz Co & 29.48 & 8.78 & \multirow{2}{*}{-.16} & \multirow{2}{*}{27.49} & \multirow{2}{*}{.873} \\
\hline Santa & Clara Co & 29.81 & 8.50 & & & \\
\hline \multicolumn{7}{|c|}{ Group Satisfaction } \\
\hline Santa & Cruz Co & 67.24 & 23.23 & \multirow{2}{*}{1.35} & \multirow{2}{*}{29.91} & \multirow{2}{*}{.187} \\
\hline Santa & Clara Co & 59.64 & 25.65 & & & \\
\hline \multicolumn{7}{|c|}{ Personal Satisfaction } \\
\hline Santa & Cruz Co & 80.14 & 16.97 & \multirow{2}{*}{.29} & \multirow{2}{*}{25.89} & \multirow{2}{*}{.773} \\
\hline Santa & Clara Co & 78.99 & 14.65 & & & \\
\hline \multicolumn{7}{|l|}{ Culture } \\
\hline Santa & Cruz Co & 147.38 & 36.96 & \multirow{2}{*}{.99} & \multirow{2}{*}{28.59} & \multirow{2}{*}{.330} \\
\hline Santa & Clara Co & 138.63 & 38.17 & & & \\
\hline
\end{tabular}


Table 9

T-Tests for Sex

\begin{tabular}{|c|c|c|c|c|c|}
\hline Variable & Mean & $\underline{S D}$ & $\underline{t}$ & $\mathrm{df}$ & $\underline{\mathrm{p}}$ \\
\hline \multicolumn{6}{|l|}{ Mission } \\
\hline Female & 31.95 & 5.56 & \multirow{2}{*}{-.49} & \multirow{2}{*}{25.05} & \multirow{2}{*}{.631} \\
\hline Male & 32.65 & 6.03 & & & \\
\hline \multicolumn{6}{|l|}{ Goals } \\
\hline Female & 32.79 & 5.60 & \multirow{2}{*}{.07} & \multirow{2}{*}{27.05} & \multirow{2}{*}{.947} \\
\hline Male & 32.70 & 5.30 & & & \\
\hline \multicolumn{6}{|l|}{ Feedback } \\
\hline Female & 25.12 & 11.41 & \multirow{2}{*}{-.64} & \multirow{2}{*}{26.47} & \multirow{2}{*}{.530} \\
\hline Male & 26.85 & 11.20 & & & \\
\hline \multicolumn{6}{|l|}{ Rewards } \\
\hline Female & 24.32 & 9.91 & \multirow{2}{*}{.01} & \multirow{2}{*}{32.43} & \multirow{2}{*}{.992} \\
\hline Male & 24.30 & 7.40 & & & \\
\hline \multicolumn{6}{|l|}{ Support } \\
\hline Female & 29.42 & 8.62 & \multirow{2}{*}{-1.16} & \multirow{2}{*}{27.93} & \multirow{2}{*}{.256} \\
\hline Male & 31.65 & 7.78 & & & \\
\hline \multicolumn{6}{|l|}{ Group Sat } \\
\hline Female & 60.29 & 26.07 & \multirow{2}{*}{-.69} & \multirow{2}{*}{30.24} & \multirow{2}{*}{.497} \\
\hline Male & 63.95 & 21.13 & & & \\
\hline \multicolumn{6}{|c|}{ Personal Sat } \\
\hline Female & 78.47 & 15.57 & \multirow{2}{*}{-1.70} & \multirow{2}{*}{36.06} & \multirow{2}{*}{.097} \\
\hline Male & 83.15 & 10.41 & & & \\
\hline \multicolumn{6}{|l|}{ Culture } \\
\hline Female & 138.76 & 39.46 & \multirow{2}{*}{-1.15} & \multirow{2}{*}{34.11} & \multirow{2}{*}{.259} \\
\hline Male & 147.10 & 27.90 & & & \\
\hline
\end{tabular}


Table 10

Analysis of Variance for Culture by Age

\begin{tabular}{lccccc}
\hline Source & $\mathrm{df}$ & Sum of Squares & Mean Squares & $\underline{\mathrm{F}}$ & $\underline{\mathrm{p}}$ \\
\hline Between Groups & 3 & 5253.6783 & 1751.2261 & 1.220 & .3050 \\
Within Groups & 129 & 185098.2916 & 1434.8705 & \\
Total & 132 & 190351.9699 & & \\
\hline Group & \multicolumn{7}{c}{ Number in Group } & Mean & SD \\
\hline Age $21-30$ & 12 & 137.58 & 32.88 \\
Age $31-40$ & 29 & 133.03 & 46.21 \\
Age $41-50$ & 63 & 138.54 & 36.25 \\
Age $51-63$ & 29 & 151.21 & 33.77 \\
Total & 133 & 140.02 & \\
\hline
\end{tabular}


satisfaction and/or school principals' communication in Santa Cruz and Santa Clara Counties in comparison to the average perceptions of managers of other organizations in the data base?) and were completed through the use of a $\underline{t}$-test for independent samples. The results of the $\underline{t}$-tests are reported in Table 11 .

Significant differences between the education organizations in the two counties surveyed and other organizations in the Lashbrook data base were obtained for mission $(\underline{t}=4.32, p<.05)$. goals $(\underline{t}=10.44, p<.05)$. group satisfaction $(\underline{t}=3.09, p<.05)$, and personal satisfaction $(\underline{t}=3.19, p<.05)$. Scores in the educational organization sample were higher for mission, group satisfaction, and personal satisfaction, and lower for goals. Thus the answer to the third research question appears to be that there are differences in teachers' perceptions in these counties of both job satisfaction and principals' communication as compared to perceptions of managers in other types of organizations in the data base.

Two disclaimers for this last set of comparisons should be noted here. First, t-values cannot be calculated from these data. The t-values are an estimate based on the following equation for degrees of freedom:

$$
d f=\frac{\left[\left(S_{1}^{2} / N_{1}\right)+\left(S_{2}^{2} / N_{2}\right)\right]^{2}}{\left.\left[\left(S_{1}^{2} / N_{1}\right)^{2} / N_{1}-1\right)\right]=\left[\left(S_{2}^{2} / N^{2}\right)^{2} /\left(N_{2}-1\right)\right]}
$$


Table 11

T-Tests for Organizations

\begin{tabular}{|c|c|c|c|c|c|}
\hline Variable & Mean & $\underline{S D}$ & $\underline{t}$ & $\underline{d f}$ & $\underline{P}$ \\
\hline \multicolumn{6}{|l|}{ Mission } \\
\hline Other ${ }^{a}$ & 78.00 & & \multirow[t]{2}{*}{$4.32^{c}$} & \multirow{2}{*}{132.05} & \multirow{2}{*}{$p<.05$} \\
\hline Education & 80.13 & 5.61 & & & \\
\hline \multicolumn{6}{|l|}{ Goals } \\
\hline Other & 87.00 & 6.30 & \multirow{2}{*}{$10.44^{c}$} & \multirow{2}{*}{132.04} & \multirow{2}{*}{$p<.05$} \\
\hline Education & 81.94 & 5.53 & & & \\
\hline \multicolumn{6}{|l|}{ Feedback } \\
\hline Other & 65.00 & 14.40 & \multirow{2}{*}{1.56} & \multirow{2}{*}{132.05} & \multirow{2}{*}{$\mathrm{p}>.05$} \\
\hline Education & 63.44 & 11.36 & & & \\
\hline \multicolumn{6}{|l|}{ Rewards } \\
\hline Other & 62.00 & 15.70 & \multirow{2}{*}{1.44} & \multirow{2}{*}{132.08} & \multirow{2}{*}{$p>.05$} \\
\hline Education & 60.79 & 9.55 & & & \\
\hline \multicolumn{6}{|l|}{ Support } \\
\hline Other & 73.00 & 11.90 & \multirow{2}{*}{1.87} & \multirow{2}{*}{132.06} & \multirow{2}{*}{$\mathrm{p}>.05$} \\
\hline Education & 74.40 & 8.51 & & & \\
\hline \multicolumn{6}{|l|}{ Group Sat } \\
\hline Other & 54.00 & 16.20 & \multirow{2}{*}{$3.09^{c}$} & \multirow{2}{*}{132.01} & \multirow{2}{*}{$\mathrm{p}<.05$} \\
\hline Education & 60.84 & 25.35 & & & \\
\hline \multicolumn{6}{|l|}{ Personal Sat } \\
\hline Other & 75.00 & 9.80 & \multirow{2}{*}{$3.19^{c}$} & \multirow{2}{*}{132.01} & \multirow{2}{*}{$\mathrm{p}<.05$} \\
\hline Education & 79.17 & 14.97 & & & \\
\hline
\end{tabular}

Note. Other refers to the thirteen other types of organizations previously included in the LS data base.

${ }^{a} \underline{N}=12,433 . \quad{ }^{b} \underline{N}=133 . \quad \underline{c}_{t} \underline{c r i t}=1.98$ for df $=120$. 
(Nie!, Hull, Jenkins, Steinbrenner, \& Bent, 1975, p. 270). Secondly, this, of course, is not an experimental comparison because no independent variables were manipulated. Further, the methods used to survey the participants in this study varied from the ways in which Lashbrook's subjects were surveyed. 
CHAPTER IV

Discussion

The previous chapter described the results of data analysis regarding the relationship between the predictor variables (mission, goals, feedback, rewards, and support) and the criterion variables (group and personal satisfaction). This chapter considers the theoretical implications of the results and discusses conclusions that can be drawn from the study, limitations of the study, and recommendations for further research.

\section{Conclusions}

The purpose of this research was to determine whether or not a relationship exists between perceptions of a principals' communication effectiveness and teacher satisfaction on the job. A review of literature integrating both communication and education research was used as a basis for generating the research questions and established the predictive efficacy of the PSM for thirteen types of organizations.

The results of this study indicate that, for teachers in Santa Cruz and Santa Clara Counties, there is a significant relationship between how they perceive their principals' communication and how satisfied they are on the job as determined by the canonical correlation of .86 . 
These results also appear to support the PSM. Leadership factors in the PSM appear to be predictors of culture (the combination of group and personal satisfaction) across educational organizations within the two participating counties. In addition, results suggest that a principals' communication of feedback is the best predictor of culture.

Teachers who rated their principals as strong in the area of feedback responded to index items indicating that their principal helps them understand how well they are performing their job, is a source of accurate information about their job performance, gives useful feedback, and gives constructive feedback. In other words, these teachers feel informed about their job performance. Such principals monitor their employees' performance and know how to initiate change when necessary.

Support and rewards appear to be the second and third best predictors of culture among teachers in the two counties with correlation coefficients of .76 and .73 , respectively. Supportiveness is defined here by index items indicating the ability and desire to help faculty members solve their job-related problems. Support is also closely associated with feedback, sharing a correlation coefficient of .82 . This indicates that a principal's knowledge and understanding of a teacher's job performance is related to the ability and desire to help. 
Communication of rewards is defined here by index items indicating principals who tie rewards to work quality, publicly recognize good work, and are perceived as being fair. As was the case with support, rewards also appear to be associated with feedback, though the relationship is not as strong $(\underline{r}=.72)$. This suggests that some feedback may also be perceived as a reward by teachers. It is important to point out that, in addition to feedback, support, and rewards indicating the strongest relationship to work culture, these variables also have the lowest mean scores overall (feedback $=64$, support $=$ 74, rewards $=61$ ). These findings are consistent with the rest of the data base (feedback $=65$, support $=73$, and rewards $=62$ ). This suggests that teachers in the respondent pool feel their principals could improve their communication of these three variables and, in doing so, might positively affect teacher satisfaction on the job.

In comparing demographic data between various respondent groups, no significant differences were obtained for county, sex, or age. These findings are consistent with previous research in that no correlation has been obtained between job satisfaction and demographic variables (Trombetta \& Rogers, 1988). Caution needs to be taken, however, in reporting such results as the insignificant differences should in no way suggest generalizable conclusions across all educational organizations. These 
results simply indicate that among the teachers surveyed, there are similar perceptions of principals' communication effectiveness as well as degrees of job satisfaction.

In comparing data obtained for the education organizations included in this study with data obtained for thirteen other types of organizations from previous studies (see Tables 1 and 2), statistically significant differences were found for mission, goals, group satisfaction, and personal satisfaction ( $\underline{p}(.05)$. While these differences may be statistically significant, they may not be meaningful for mission and personal satisfaction. Mean scores for educational organizations and other organizations are fairly close: mission $=80,78$; personal satisfaction $=$ 79, 75. Teachers' perceptions of group satisfaction resulted in a higher mean score than that for other organizations in the data base $(\underline{M}=61,54)$. Generalizations cannot be drawn from these findings because of the difference in sampling procedures and sample size between educational organizations and other organizations $(\underline{N}=133$; $\underline{N}=12,433)$. Although findings suggest that teachers in the respondent pool perceive themselves as being more satisfied than other employees in the data base, this study cannot provide answers as to why that is the case. Many factors could be involved, such as location, number of working days per year, more freedom on the job, a greater satisfaction with the work itself, opportunity for professional growth, 
or again, sampling procedures. Further research would be needed to see whether these differences hold with other samples.

Table 12 shows a comparison of teachers' perceptions of principals' communication effectiveness with perceptions of managers in the data base. Here, predictor variables are listed beginning with the lowest mean score and ending with the highest. Table 13 presents a comparison of best predictors of culture to least significant predictors of culture according to the canonical coefficients displayed in Table 7. These tables indicate that, although certain statistically significant differences were noted, teachers in Santa Cruz and Santa Clara Counties perceive their principal's communication effectiveness similarly to employees from other organizations in terms of variance accounted for by the different predictor variables in the $\operatorname{mode1}$.

One comparison is that both groups appear to perceive themselves as being more satisfied with their jobs than their work groups are as a whole. In addition, lists for both groups in Table 13 are ordered in the same way, supporting Lashbrook's (1984) findings that feedback and rewards are the best predictors of culture, and mission and goals are the least significant predictors of culture.

It is important to point out that goals, the predictor variable receiving the highest score for communi- 
Table 12

Comparison of Perceptions of Communication Effectiveness and Job Satisfaction

Educational Organizations

Other Organizations

\begin{tabular}{llll}
\hline Variable & Mean & Variable & Mean \\
Rewards & 61 & Rewards & 62 \\
Feedick & 64 & Feedback & 73 \\
Support & 74 & Support & 78 \\
Mission & 80 & Mission & 87 \\
Goals & 82 & Goals & 75 \\
Personal Sat & 79 & Personal Sat & \\
\hline
\end{tabular}

Note. Other organizations refers to the thirteen other types of organizations previously included in the LS data base (Lashbrook, 1984). 
Table 13

Comparison of Predictors of Culture

\begin{tabular}{llll}
\hline Educational & Organizations & Other Organizations \\
\hline$\frac{\text { Best }}{\text { Predictor }}$ & Feedback & $\frac{\text { Best }}{\text { Predictor }}$ & Feedback \\
& Rewards & Rewards \\
& Support & Support \\
$\frac{\text { Least }}{\frac{\text { Significant }}{\text { Predictor }}}$ & Goals & $\frac{\text { Least }}{\text { Significant }}$ & Goals
\end{tabular}

Note. Other organizations refers to the thirteen other types of organizations previously included in the LS data base (Lashbrook, 1984). 
cation effectiveness, turned out to be the least significant predictor of culture. On the other hand, feedback, the predictor variable receiving one of the lowest scores for communication effectiveness, was found to be the best predictor of culture. This suggests that, for both groups, improvement in a manager's communication of feedback could result in increased satisfaction on the job for employees.

\section{Limitations of the Study}

When drawing conclusions from a study it is necessary to point out any limitations involved in the methods used. While it would be impossible to account for all the conditions that might have had some bearing on who was chosen to respond to the survey and how each person chose to respond, it is possible to discuss the more obvious limitations that might have had some influence on the findings.

One limication of this study relates to the fact that surveys were mailed to each participating school and placed in teachers' mailboxes according to grade level. This may have resulted in some teachers participating who were new to the school and had spent a limited amount of time with the principal before responding to the survey. Additionally, it is most likely that some teachers who were not new to a school were responding to a principal who was new, posing a possible problem with accuracy of 
responses.

Another limitation of this study involves the difference in sample size between the two participating counties. Santa Cruz County's sample size was 21 , in comparison to 112 for Santa Clara County. This difference should not affect the canonical correlation or ANOVA analyses, but may have had some bearing on t-test results because of possible nonhomogeneity of variance.

The next limitation of this study has to do with the terminology used in the survey questions. A few teachers commented on the questionnaire that they had trouble understanding the meaning of "objectives of your faculty" in items seven, nine, and ten (see Appendix A). Academic objectives are often developed by district curriculum committees rather than by individual faculties, so the wording may have been confusing to respondents.

Another term that some teachers indicated confusion about was "reward" (items 19-24). Comments included, "The word acknowledgment would be a better choice," "It's not the principal.'s place to reward," "The principal has no control over our salaries," and "The word reward is unclear." Others simply underlined the word reward and added a question mark.

A further Iimitation of this study is that only one teacher responded to each principal's communication effectiveness. This was done in order to allow all 
elementary schools in both counties to be included in the study, rather than involve more teachers from just a few schools. Although these evaluations give a sense of the larger picture, allowing entire faculties from participating schools to respond to the LS would provide a more accurate assessment of a principal's communication and would permit comparisons to be made between individual schools.

\section{Recommendations for Further Research}

This study has provided an empirical examination of communication effectiveness and job satisfaction in educational organizations within two counties. The purpose of this study, which was to determine whether or not a relationship exists between these two organizational concerns, was fulfilled for Santa Cruz and Santa Clara Counties. A significant correlation of .86 was found, but caution must be exercised before making any generalizations beyond the scope of this research. The process of establishing norms for educational organizations, which was begun by this study, needs to be continued in order to draw further conclusions.

Future research in this area should include possible modification of LS measures to make it more appropriate for educational organizations. It would be preferable to involve educators in this process who are familiar with 
educational jargon and the meanings that might be applied to certain terms by those in the field. This would require new tests to be conducted for instrument reliability.

A much more involved process would be to develop a new instrument altogether. As stated in Chapter I, there are reliable instruments that exist specifically to evaluate a principal's leadership, but none was found that in-. cluded job satisfaction questions. Several instruments are self-reports for principals, rather than ones that would provide feedback from teachers. A new instrument could allow analysis of the same variables, but be tailored to the unique needs of educational organizations. - Finally, further research could include larger sample sizes whereby entire faculties from participating schools could be asked to respond to their principals' communication effectiveness. As mentioned earlier, this might allow a more accurate assessment, as well as provide interested principals with reliable feedback as to how they are perceived by faculty members.

This study lends support to the explanatory efficacy of the PSM for educational organizations. This is an important finding because it's contradictory to the beliefs of popular culture that service organizations and other types of organizations are different with respect to how they can and should be managed, and that public sector managers don't know how to manage. The main claim of the 
PSM is that leadership performance, which involves communication of mission, goals, feedback, rewards, and support, is strongly and positively related to work unit satisfaction. As the model predicted, teachers in this study were more satisfied on the job if they perceived their principals as being effective communicators in those five areas. Dissemination of this information might positively influence the approach principals take to the leadership of their schools. 
REFERENCES 


\section{REFERENCES}

Arvey, R.D., \& DeWhirst, H.D. (1976). Goal-setting attributes, personality variables, and job satisfaction. Journal of Vocationa1. Behavior, 9, 179-189.

Barnes, L.B. (1981). Managing the paradox of organizational trust. In J.N. Williamson (Ed.), The leadermanager (pp. 465-478). New York: John Wiley \& Sons.

Bennis, W. (1983). Four traits of leadership. In J.N. Williamson (Ed.), The leader-manager (pp. 77-89). New York: John Wiley \& Sons.

Berlew, D.E. (1974). Leadership and organizational excitement. California Management Review, 17 (2), $21-30$.

Borden, G.A. (1977). Constructs for a theory in human communication. In B. Ruben (Ed.), Communication yearbook I (pp. 355-361). New Brunswick: Transaction Books.

Bradford, D., \& Cohen, A. (1984). Managing for excellence. New York: John Wiley \& Sons.

Brandt, R. (1987). On leadership and student achievement: A conversation with Richard Andrews. Educational Leadership, 45, 9-16.

Della-Dora, D. (1987). Quality supervision and organization for quality teaching. Educational Leadership, 44 (8), 35-38.

Donaldson, G.A. (1987). The Maine approach to improving principal leadership. Educational Leadership, 45 ,

pp. 43-45.

Driscoll, J.W. (1973). Trust and participation in organizational decision-making as predictors of satisfaction. Academy of Management Journa1, $21,44$.

Fairbanks, J.A., \& Prue, D.M. (1982). Developing performance feedback systems. In L.W. Frederikson (Ed.), Handbook of organizational behavior management (pp. 167-183). New York: John Wiley \& Sons.

Fairman, M., \& Clark, E. (1985). Moving toward excellence: A model to increase student productivity. NASSP Bulletin, 70, 45-51. 
Falcione, R.L. (1974). Communication climate and satisfaction with immediate supervision. Journal of Applied Communication, 2, 13-20.

Falcione, R.L., McCroskey, J.C., \& Daly, J.N. (1977). Job satisfaction as a function of employee's communication apprehension, self-esteem, and perceptions of their immediate supervisors. In B. Ruben (Ed.), Communication yearbook I (pp. 363-375). New Brunswick: Transaction-International Communication.

Fischer, B. (Ed.). (1986-87). Today's education [Special issue]. NEA Today, 5 , (1).

Fisher, B.A. (1988). Leadership: When does the difference make a difference? In R. Hirokawa \& M.S. Poole (Eds.), Communication and group decision-making (pp. 197215). Beverly Hills: Sage.

Ford, J.D. (1987). The decline of confidence in leadership. The Clearing House, 60, 218.

Goldhaber, G.M. (1983). Organizational communication. Dubuque, IA: William C. Brown.

Greene, C.N. (1975). The reciprocal nature of influence between leader and subordinate. Journal of Applied Psychology, 60, 187-193.

Greene, C.N. (1977). The satisfaction performance controversy. In K. Magnusen (Ed.), Organizational design, development, and behavior: A situational view (pp. 190-214). Glenview, Illinois: Scott Foresman.

Habegger, P.J., \& Lashbrook, W.B. (1981). An empirical examination of perceptual differences/similarities for managers and their subordinates concerning job satisfaction. Eden Prairie, MN: Wilson Learning Corporation.

Hackman, J.R., \& Lawler, E.E. (1971). Employee reactions to job characteristics [monograph]. Journal of Applied Psychology, 55, 259-286.

Hallinger, P., \& Murphy, J.F. (1987). Assessing and developing principal instructional leadership. Educational Leadership, 45, 54-61. Herzberg, F. (1966). Work and the nature of man. New York:
World. 
Herzberg, F. (1968), One more time: How do you motivate employees? In J.N. Williamson (Ed.), The leader-manager (pp. 433-448). New York: John Wiley \& Sons.

Herzberg, F. (1974). The wise old turk. Harvard Business Review, 52, 70-80.

Heyns, B. (1988). Educational defectors: A first look at teacher attrition in the NLS-72. Educational Researcher, 17, 24-32.

Hunt, J.G., \& Hill, J.W. (1977). The new look in motivation theory for organizational research. In K. Magnusen (Ed.), Organizational design, development, and behavior: A situational view. Glenview, Illinois: Scott-Foresman.

Hunt, J.G., \& Osborn, R.N. (1978). Relations of discretionary and nondiscretionary leadership to performance and satisfaction in a complex organization. Human Relations, 31, 507-523.

Hurt, H.T., \& Teigen, C.W. (1977). The development of a measure of perceived organizational innovativeness. In B.D. Ruben (Ed.), Communication yearbook I (pp. 377385). New Brunswick: Transaction-Interaction Communcation.

Kanter, R.M. (1983). The change masters. New York: Simon \& Schuster.

Keller, R.T. (1975). Role conflict and ambiguity: Correlates with job satisfaction and values. Personnel Psychology, 23, 57-64.

Kerr, S. (1975). On the folly of rewarding A, while hoping for B. In J.N. Williamson (Ed.), The leadermanager (pp. 417-432). New York: John Wiley \& Sons.

Knutson, P.K., \& Lashbrook, W.B. (1976). Communication apprehension as an antecedent to social style. Paper presented to the Speech Communication Association convention, San Francisco.

Koehler, J.W., Anatol, K.W., \& Applbaum, R.L. (1976). Organizational communication: Behavioral perspectives

Lashbrook, W.B. (1979). ManCom phase 1 alpha report for Finning Tractor. Eden Prairie, MN: Wilson Learning Corporation. 
Lashbrook. W.B. (1980). ManCom phase II alpha report for Mountain Bell. Eden Prairie, MN: Wilson Learning Corporation.

Lashbrook, W.B. (1981). Management as a performance system. Paper presented to the Behavioral Science Interest Group, Western States Communication Association.

Lashbrook, W.B. (1984). Management as a performance system. In J.N. Wiliiamson (Ed.), The leader-manager (pp. 125136). Eden Prairie, MN: Wilson Learning Corporation.

Lawler, E.E. (1974). For a more effective organizationmatch the job to the man. In J.N. Williamson (Ed.), The leader-manager (pp. 449-459). New York: John Wiley

Leithwood, K.A. (1987). Using the principal profile to assess performance. Educational Leadership, 45, 63-66.

Likert, R. (1985). Excerpt from the human organization. In Wilson Learning Corporation, Leadership growth opportunities (p. 13). Eden Prairie, MN: Author.

Likert, R., \& Likert, J.C. (1976). New ways of managing conflict. New York: McGraw-Hill.

Lincoln, J.R., Hanada, M., \& Olson, J. (1981). Cultural orientations and individual reactions to organizations: A study of employees of Japanese-owned firms. Administrative Science Quarterly, 26, 93-115.

Locke, E.A. (1976). Nature and causes of job satisfaction. In M.D. Dunnette (Ed.), Handbook of industrial and organizational psychology (pp. 1297-1349). Chicago:

MacAdam, M. (1986). Building leadership: Peak performance skills. Thrust for Educational Leadership,
$15,42-45$.

Manasse, A.L. (1984). A policymaker's guide to improving conditions for principals' effectiveness. Alexandria, VA: National Association of State Boards of Education.

Manasse, A.L. (1985). Improving conditions for principal effectiveness: Policy implications of research. The Elementary School Journal, 85, 138-162.

McGregor, D.M. (1960). The human side of enterprise. New York: McGraw-Hil1. 
Michael, D.N. (1976). On the importance of feedback and the resistances to it. In J.N. Williamson (Ed.), The $\frac{1 \text { eader-manager }}{\text { \& Sons. }}$ (pp. 385-401). New York: John Wiley

Mintzberg, H. (1973). The nature of managerial work. New York: Harper \& Row.

Morrisey, G.L. (1977). Management by objectives and results for business and industry (2nd ed.). Reading, MA: Addison-Wesley.

Nie, N.H., Hul1, C.H., Jenkins, J., Steinbrenner, K., \& Bent, D. (1975). Statistical package for the social sciences (2nd ed.). New York: McGraw Hill.

Niehouse, O.L. (1988). Leadership concepts for the principal: A practical approach. NAASP Bulletin, $\underline{72}, 50-60$.

Norton, R.W. (1978). Foundation of a communication style construct. Human Communication Research, 4 , 99-112.

Pedalino, E., \& Gamboa, V.U. (1974). Behavior modification and absenteeism: Intervention in one industrial setting. Journal of Applied Psychology, 59, 694-698.

Peters, T.J., \& Waterman, R.H. (1982). In search of excellence. New York: Harper \& Row.

Peterson, K.D. (1982). Making sense of principals' work. The Australian Administrator, $2,1-4$.

Peterson, K.D. (1986). Principals' work, socialization, and training: Developing more effective leaders. Theory into Practice, 25, 251-255.

Phillips, J.R., \& Kennedy, A.A. (1980). Shaping and managing shared values. San Francisco: McKinsey \& Co.

Pitner, N.J. (1982). Training of the school administrator: State of the art. Report prepared for the Center for Educational Policy and Management, University of Oregon, Eugene, OR.

Reilly, D.H. (1986). Educational leadership: The missing element. Education, 106, 421-428.

Richmond, V.P., \& McCroskey, J.C. (1979). Management communication style, tolerance for disagreement, and innovativeness as predictors of employee satisfaction: 
A comparison of single-factor, two-factor, and multiple-factor analysis. In D. Nimmo (Ed.), Communication yearbook III (pp. 359-373). New Brunswick: Transaction Books.

Richmond, V.P., McCroskey, J.C., Davis, L.M., \& Koontz, K.A. (1980). Perceived power as a mediator of management communication style and employee satisfaction: A preliminary investigation. Communication Quarterly, $\underline{28}, 31-46$.

Richmond, V.P., Wagner, J.P., \& McCroskey, J.C. (1983). The impact of perceptions of leadership style, use of power, and conflict management style on organizational outcomes. Communication Quarter1y. 31, 27-36.

Scanlan, B.K. (1976). Determinants of job satisfaction and productivity. Personnel Journa1, 55, 12-14.

Scheidel, T.M. (1987, October). The study of leadership. Unpublished manuscript. University of Utah, B. Aubrey Fisher Memorial Lecture, Salt Lake City.

Schneider, B., \& Bartlett, C.J. (1968). Individual differences and organizational climate. Personnel Psychology, 21, 323-333.

Seashore, S.E., \& Bowers, D.G. (1977). Durability of organizational change. In K. Magnusen (Ed.), Organizational design, deveiopment, and behavior (pp. 74-93). Glenview, Illinois: Scott Foresman.

Sims, H.P., \& Szilagyi, A.D. (1975). Leader reward behavior and subordinate satisfaction and performance. Organizational Behavior and Human Performance, 14, $426-438$.

Smith, P.C., Kenda11, L.M., \& Hulin, C.L. (1969). Measurement of satisfaction in work and retirement. Chicago: Rand-McNally.

Steers, R.M. (1976). Factors affecting job attitude in goal-setting environments. Academy of Management Journa1, 19, 6-16.

Timbers, E. (1974). Strengthening motivation through communication. In R. Huseman, C. Logue, \& D. Freshley (Eds.), Readings in interpersonal and organizational communication (2nd ed.) (pp. 126-142). Boston: Holbrook Press. 
Trombetta, J.J., \& Rogers, D.P. (1988). Communication climate, job satisfaction, and organizational commitment. Management Communication Quarterly, 1, 494-514.

Williamson, J.N. (1984). The leader-manager. New York: John Wiley \& Sons.

Wilson Learning Corporation. (1981a). Management performance inventory. Eden Prairie, MN: Author.

Wilson Learning Corporation. (1981b). The statistical adequacy of the Leadership Growth Opportunities Survey. Eden Prairie, MN: Author.

Wylie, R. (1961). The self-concept: A critical survey of pertinent researchliterature. Lincoln, NE: University of Nebrasks Press.

Yankelovich, C., \& Immerwahr, J. (1983). Why the work ethic isn't working. New York: Public Agenda Foundation. 
APPENDIXES 
APPENDIX A

The Survey Instrument

Dear Fellow Teacher:

Enclosed you will find a survey on principal leadership and teacher satisfaction. One teacher from each elementary school in Santa Cruz and Santa Clara Counties has been chosen to participate and you're the representative from your school who has been selected. Your responses are completely anonymous. The survey takes ten-fifteen minutes to complete, and a return envelope has been provided for your convenience.

This study is important because it has never been attempted in school systems before and can provide vital informaiton to anyone associated with the field of education. For these reasons, your participation in this study is greatly appreciated.

If you have any questions, or would like further information, please call Kanda Whaley at 924-5370, or Dr. Tim Hegstrom at 924-5372.

Thank you for your help!

Sincerely,

Kanda W. Whaley

San Jose State University

Communication Studies Department 


\section{PLEASE NOTE:}

Copyrighted materials in this document have not been filmed at the request of the author. They are available for consultation, however. in the author's university library.

These consist of pages:

78-82: Leadership Survey 
APPENDIX B

Leadership Survey Questions

Pertaining to Each Variable

\begin{tabular}{lcr}
\hline VARIABLE & EMPHASIS QUESTIONS* & P:RACTICE QUESTIONS* \\
\hline Mission & 1,2 & $3,4,5,6$ \\
Goals & 7,8 & $9,10,11,12$ \\
Feedback & 25,26 & $27,28,29,30$ \\
Rewards & 19,20 & $21,22,23,24$ \\
Support & 13,14 & $15,16,17,18$ \\
\hline
\end{tabular}

VARIABLE

QUESTIONS*

Group Satisfaction $\quad 31,32,33,34,35,36$

Personal Satisfaction $37,38,39,40$

*For complete questions see the Leadership Survey (Appendix A) 